\title{
Aspergillus niger as the Source of Ochratoxin A of Contaminated Pyrus communis in Taif Market
}

\author{
Yassmin M. Shebany ${ }^{1,2^{\star}}$, Youssuf A. Gherbawy ${ }^{1}$ and Shoroug N. Al-Garni ${ }^{2}$ \\ ${ }^{1}$ Department of Botany, Faculty of Science, South Valley University, Qena, Egypt. \\ ${ }^{2}$ Department of Biology, Faculty of Science, Taif University, Taif, Saudi Arabia.
}

\begin{abstract}
Authors' contributions
This work was carried out in collaboration between all authors. Author YMS managed the literature searches, wrote the first draft of the manuscript, shared in the final revision of the manuscript. Author

YAG designed the study, wrote the protocol, shared in the final revision of the manuscript. Author

SNA carried out practical experiments, performed the statistical analysis managed the literature searches. All authors read and approved the final manuscript.
\end{abstract}

Article Information

DOI: 10.9734/ARRB/2018/v30i430018

Editor(s):

(1) Dr. Moacir Marocolo, Physiology and Human Performance Research Group, Department of Physiology, Federal University of Juiz de Fora, Brazil.

(2) Prof. George Perry, Dean and Professor of Biology, University of Texas at San Antonio, USA.

Reviewers:

(1) Mohamed Ibrahim Mohamed Ibrahim, National Research Centre, Egypt.

(2) Luis Alberto Ramirez Camejo, Purdue University, USA.

Complete Peer review History: http://www.sdiarticle3.com/review-history/47496

Original Research Article

Received 25 October 2018

Accepted 19 February 2019

Published 01 March 2019

\begin{abstract}
Fruits are one of the most important agricultural products that supply the body with vitamins and essential minerals elements, but it is contaminated by fungi during the period of growth, harvesting and storage. A. niger is one of the species that grows on the fruit during the period of storage, and secretes mycotoxins especially ochratoxin $A$. This study was conducted with the purpose of isolating and identifying different strains of $A$. niger from 20 samples of pear collected from Taif markets and to determine the ability of these strains to produce OTA. It was observed that showed that out of 20 pear samples collected, 19 samples were detected to be contaminated with different strains of $A$. niger and the strains were able to produce OTA. From 27 isolates of $A$. niger which was used to test the ability of production OTA, 10 strains only produced OTA. The range of OTA in all strains were 0.18 to $9.5 \mathrm{ppb}$. Representative 27 strains of ochratoxigenic and non ochratoxigenic black Aspergilli isolated were subjected for detection of ochratoxin biosynthesis genes, by using two sets of primer for two genes involved in ochratoxin biosynthetic pathway. Bands of the
\end{abstract}


fragments of PKS15C-MeT and PKS15KS genes visualized at 998 and 776 bp, respectively. Whereas, the presence of four tested genes is not sufficient marker for differentatin between aflatoxigenic and non aflatoxigenic isolates.

Keywords: Black aspergilla; ochratoxin A; pyrus communis; DNA isolation; PKS15C-MeT and PKS15KS genes.

\section{INTRODUCTION}

Fruits are commercially and nutritionally vital food. Fruits play a vital role in human nutrition by supplied with the required growth factors as vitamins and essential minerals, fats, and oil within the right proportion to take care of growth and development on humans, daily diet maintaining a decent and traditional health [1]. Because of environmental condition, pests, inadequate downfall and fungi attack, fruits and vegetable have serious challenges to their existence [1]. Over the years, fungal caused several of disease like rot diseases that provoke severe losses of agricultural and horticultural crops each year $[2,3]$. One of the most vital limiting factors that impact the economic value of fruits is the comparatively short shelf-life period caused by pathogens. About $20-25 \%$ of the harvested fruits are deteriorated by pathogens throughout post-harvest handling even in advanced countries [4,5].

Fungi are treated as an important post-harvest losses agent of many different fruits, depended on variety, season and production area amid alternative factors [6,7]. Many of crop diseases are caused by fungi as the most crucial and common pathogens. Fungi colonized many of fruits and vegetables during storage and transportation [8]. Rotted fungi are considered biological agents that have ability to produce a wide range of enzyme, which able these fungi to colonize the fruits. Mould growth depends on several factors such $\mathrm{pH}$, water activity (aw), temperature, atmosphere, time, etc. [9].

A. niger is a fungus and one the most widespread species of the genus Aspergillus. It causes a disease called black mold on fruits and vegetables similar to grapes, onions and peanuts and is a common contamination of food. A. niger is common in soil and many of environments. $A$. niger produce many of mycotoxins such as OTA [10,11], fumonisins B2, B4 and B6 [12,13,14], as well as numerous other compounds with poorly investigated activities [15,16], such as heptocarcinogenic, nephrogenic which are immunological in nature. In addition, this fungus is also causative agent for many rot diseases in plants [17]. Black Aspergilli (Aspergillus section Nigri) are useful in food mycology, medical mycology and biotechnology, often occurring in indoor environments $[18,19]$. several species of fungi cause food spoilage, however are also utilized in the fermentation industry to provide varied enzymes and organic acids [20].

Isolates of $A$. niger have the ability to produce OTA, then, many concerns have arisen not only for their biotechnological safety but also for their food safety risk, due to their common presence in numerous commodities $[21,22,23,24]$. OTA have properties of a potent nephrotoxin and has teratogenic, immunosuppressive and carcinogenic properties [25]. OTA entry to humans and animals is caused by cereals and cereal based food and feed which considered the main contributors, since OTA is stable under traditional food processing operation conditions and it is carried-over from raw materials to processed products [26]. At recent days, mycotoxin issues has widened, there are many reports showed the ability of $A$. niger to produce fumonisin B2 (FB2) along with OTA $[26,27,28]$. The International Agency for Research on Cancer classified OTA as a possible carcinogen to humans (group 2B) [25]. Many varieties of food product within the markets are reportable to be contaminated with OTA. These include tree nuts, peanuts, figs, melon seed, pumpkin seed, sesame seed, sunflower seed, lotus seed, corn seed, red pepper, white pepper, mixed spices, rice, corn, mixed cereals, chilies, and coconut [29].

This study aimed for the isolation and identification of different strains of $A$. niger from 20 samples of pear collected from Taif markets and the ability of these strains to form OTA.

\section{MATERIALS AND METHODS}

\subsection{Collection of Samples}

Twenty samples showing rot symptoms of Pyrus communis (Pear) were collected from different 
markets and vendors in Taif city during OctoberDecember 2015 to isolate black Aspergilli.

\subsection{Isolation of Black Aspergilla}

Isolation was performed by serial dilution technique [30], $10 \mathrm{~g}$ from Pyrus communis samples at the margin of diseased/ healthy tissue were removed and soaked in $100 \mathrm{ml}$ sterilized distilled water that have been put in the shaking incubator for $30 \mathrm{~min}$. Thereafter, $1 \mathrm{ml}$ aliquots from serial dilution were inoculated onto three plates containing malt extract agar medium (MEA) and then incubated at $27^{\circ} \mathrm{C}$ for $5-7$ days and the developing fungi were counted and identified. At the end of the incubation period, colonies black Aspergilli was counted and were conducted following calculations for account of isolates:

\subsubsection{Determination of Ota ability of black Aspergilli species isolates}

Ochratoxin-producing ability of the isolates was performed by cultivating black aspergilli in czapek yeast autolysate agar medium (CYA) $(\mathrm{g} / \mathrm{L}$; sucrose 30.00 , sodium nitrate 2.00 , magnesium glycerophosphate 0.50 , potassium sulfate 0.35 , potassium chloride 0.50 , ferrous sulfate 0.01 , agar- agar 15.00$)$ supplemented with $(5.0 \mathrm{~g} / \mathrm{L})$ yeast extract [31] for 5 days at $27^{\circ} \mathrm{C}$.

OTA was extracted by grinding the moldy agar $(20 \mathrm{~g})$ in blender for $1 \mathrm{~min}$ with methanol $(100 \mathrm{ml})$ containing $0.5 \% \mathrm{NaCl}$. The mixture was then filtered through a fluted filter paper $(24 \mathrm{~cm})$, and the filtrate was diluted (1:4) with $1 \times 0.1 \%$ Tween PBS (Phosphate Buffered Saline) and refiltered through a glass-fiber filter paper. Two milliliters of the glass-fiber filtrate were placed on OchraTest columns (VICAM, Watertown, MA, USA) and allowed to elute at 1-2 drops/sec. The columns were washed two times with $10 \mathrm{ml}$ of $1 \times 0.1 \%$ Tween PBS and $10 \mathrm{ml}$ of Phosphate Buffered Saline (PBS), respectively. Then, OTA was eluted from the column with $1.5 \mathrm{ml}$ OchraTest ${ }^{\mathrm{TM}}$ Eluting Solution and OTA concentration was read in a recalibrated VICAMSeries-4 fluorometer after 60 seconds.

\subsubsection{Extraction of genomic DNA}

Mycelial cultures were harvested from potato dextrose broth (PDB) grown for 8 to $24 \mathrm{~h}$ in $10-\mathrm{ml}$ tubes $\left(3 \mathrm{ml}\right.$ of culture) or at $30^{\circ} \mathrm{C}(225 \mathrm{rpm})$ by filtering them through Whatman paper (Fisher
Scientific, Inc., Pittsburgh, Pa.), washed according to the manufacturer's instructions, and then blotted dry.

DNA extraction was performed with an Epicentre kit but with a modification of the manufacturer's protocol. Approximately $200 \mathrm{mg}$ of washed mycelia was added to a $1.7-\mathrm{ml}$ micro centrifuge tube. The step involving grinding in liquid nitrogen was omitted; instead, $450 \mu \mathrm{l}$ of yeast cell lysis solution and $1 \mu \mathrm{l}$ of a $50-\mu \mathrm{g} / \mathrm{ml}$ concentration of proteinase $\mathrm{K}$ were added to the tubes. The tubes were vortexed for $10 \mathrm{~s}$, incubated in a $65^{\circ} \mathrm{C}$ heating block for $1 \mathrm{~h}$, and then chilled on ice for $5 \mathrm{~min}$. Next, $225 \mu \mathrm{l}$ of protein precipitation reagent was added, and the tubes were vortexed for $5 \mathrm{~s}$. The suspensions were then centrifuged at $20,800 \mathrm{~g}$ for $10 \mathrm{~min}$ to pellet cellular debris. The supernatant $(\sim 500 \mu \mathrm{l})$ was transferred to a new tube, spun again to remove any residual cellular material, and then transferred to a new tube. An equal volume of isopropanol was added, and the tubes were gently inverted several times to precipitate the DNA, which was then pelleted by centrifugation at $20,800 \mathrm{~g}$ for $10 \mathrm{~min}$. Pellets were washed with $70 \%$ ice-cold ethanol, centrifuged, and then vacuum dried. DNA was resuspended in 50 to $100 \mu \mathrm{l}$ of Tris-EDTA and then treated with $2 \mu \mathrm{l}$ of a $5-\mathrm{mg} / \mathrm{ml}$ concentration of RNase $A$ at $65^{\circ} \mathrm{C}$ for $1 \mathrm{~h}$ [32]. Finally, the DNA quantity and quality were checked by electrophoresis on a $0.8 \%$ agarose gel, revealed with ethidium bromide and visualized by UV trans-illumination.

\subsubsection{Molecular detection of OTA biosynthetic genes in ochratoxigenic species of black Aspergelli}

Two primer described by [33] sets were used for the specific detection of two OTA genes.

The first one, denoted PKS15C-MeT (5'GCTTTCATGGACTGGATG and 5'CATTTCGTTGATCCCATCG). Reactions were incubated for $2 \mathrm{~min}$ at $95^{\circ} \mathrm{C}$, followed by 35 cycles of $45 \mathrm{~s}$ at $94^{\circ} \mathrm{C}, 50 \mathrm{~s}$ at $62^{\circ} \mathrm{C}$ and $1 \mathrm{~min}$ at $72^{\circ} \mathrm{C}$. Amplification cycles finished with $5 \mathrm{~min}$ incubation at $72^{\circ} \mathrm{C}$. Expected Results: Amplicon SIZE 998 bp only on positive strains.

The second pair, named PKS15KS (5'CAATGCCGTCCAACCGTATG and 5'CCTTCGCCTCGCCCGTAG). Reactions were incubated for $4 \mathrm{~min}$ at $94^{\circ} \mathrm{C}$, followed by 35 cycles of $45 \mathrm{~s}$ at $94^{\circ} \mathrm{C}, 50 \mathrm{~s}$ at $60^{\circ} \mathrm{C}$ and $1 \mathrm{~min}$ at $72^{\circ} \mathrm{C}$. Amplification cycles finished with $5 \mathrm{~min}$ 
incubation at $72^{\circ} \mathrm{C}$. Expected Results: Amplicon SIZE 776 bp only on positive strains.

\section{RESULTS}

Three species belonging to black Aspergelli were isolated and identified from Pyrus communis fruit on MEA medium at $27^{\circ} \mathrm{C}$ (Tables 1 and 2).

The total counts of fungi from Pyrus communis fluctuated between 0-27 isolates with the highest count being estimated in samples number 14 (27 isolates), while the lowest number of isolates were recovered from samples number $3,6,7$, and 8 ( 1 isolate), whereas sample number 4 not contaminated by this species (Table 2). According to the average total counts (ATC) of all black Aspergilli collected from 20 Pyrus communis fruit samples, A.niger was the most common species, which recovered from $70 \%$ of the samples, matching $73.4 \%$ of total black Aspergilli. In the individual sample the count of this species ranged from 1-23 colonies and the highest count was observed in sample no. 14 (Tables 1 and 2).

\subsection{Quantitative Determination of OTA}

All black Aspergilli species collected from the investigated samples represented with single isolate from each sample of Pyrus communis fruits collectively were tested for OTA potentials. It was detected at varying degrees and estimated by part per billion.

Table (3) showed the results of OTA production, where only two well know ochratoxigenic species were detected ( $A$. niger and $A$. tubingensis).

Among isolates of black aspergilli, the ranges of OTA in all strains were $0.18-9.5 \mathrm{ppb}$. A. niger (SNM7 strain) showed the highest level of OTA (9.5 ppb) and $A$. niger (SNM22 strain) showed the lowest level of OTA (0.18 ppb). The production level of OTA from $A$. niger (SNM15 strain), (SNM19 strain), (SNM20 strain) and
(SNM25 strain) were 2.4, 2.5, 1.2, and $0.95 \mathrm{ppb}$, respectively. and the production level of OTA from $A$. tubingensis (SNM13 strain), (SNM16 strain), (SNM17 strain) and (SNM26 strain) were $0.84,1.2,0.3$ and $0.65 \mathrm{ppb}$, respectively.

Whereas, OTA disappeared in all $A$. awamori isolates (SNM3 strain), (SNM8 strain), (SNM10 strain) and (SNM18 strain). Also, OTA disappeared from 12 isolates (SNM 1, 2, 4, 5, 9, $11,12,14,21,23,24$ and 27) of $A$. niger and one isolate (SNM6) of $A$. tubingensis.

\subsection{Detection of Some of OTA Biosynthesis Genes}

Representative 27 strains of ochratoxigenic and non ochratoxigenic black aspergilli isolates were subjected for detection of ochratoxin biosynthesis genes.

Polymerase chain reaction (PCR) was applied using two sets of primer for two genes involved in ochratoxin biosynthetic pathway. Bands of the fragments of PKS15C-MeT and PKS15KS genes visualized at 998 and $776 \mathrm{bp}$, respectively (Fig. 1).

Table 4 explained the total ochratoxin and ochratoxigenic genes (PKS15C-MeT and PKS15KS) detected in 27 strains of ochratoxigenic black aspergilli isolates collected from Pyrus communis samples. From those 27 strains, $A$. niger (SNM7, and 19), and $A$. tubingensis (SNM16, and 26) contained the two OTA biosynthesis genes. But, A. niger (SNM20, and 22) contained only PKS15C-MeT gene, while $A$. niger (SNM15, and 25) and A. tubingensis (SNM17) contained only PKS15KS gene. On the other hand, 17 non ochratoxigenic strains showed no bands, which means that, there is deletion in targeted genes in this isolates. All $A$. awamori strains (SNM3, 8, 10, and 18), A. niger strains (SNM1, 2, 4, 5, 9, 11, 12, 14, 21, 23, 24, and 27), and $A$. tubingensis strain (SNM6) showed no bands.

Table 1. Counts (as colonies in every sample) of Aspergillus section Nigri recovered from 20 Pyrus communis fruit on MEA medium at $27^{\circ} \mathrm{C}$

\begin{tabular}{llllllllllllllllllllll}
\hline Species & \multicolumn{1}{c|}{ Samples } & Total \\
& $\mathbf{1}$ & $\mathbf{2}$ & $\mathbf{3}$ & $\mathbf{4}$ & $\mathbf{5}$ & $\mathbf{6}$ & $\mathbf{7}$ & $\mathbf{8}$ & $\mathbf{9}$ & $\mathbf{1 0}$ & $\mathbf{1 1}$ & $\mathbf{1 2}$ & $\mathbf{1 3}$ & $\mathbf{1 4}$ & $\mathbf{1 5}$ & $\mathbf{1 6}$ & $\mathbf{1 7}$ & $\mathbf{1 8}$ & $\mathbf{1 9}$ & $\mathbf{2 0}$ & \\
\hline A. awamori & 2 & 0 & 0 & 0 & 2 & 0 & 1 & 0 & 0 & 0 & 0 & 0 & 0 & 0 & 0 & 1 & 1 & 0 & 4 & 0 & 11 \\
A. niger & 10 & 10 & 1 & 0 & 0 & 1 & 0 & 1 & 8 & 0 & 1 & 6 & 13 & 23 & 6 & 11 & 0 & 7 & 0 & 4 & 102 \\
A. tubingensis & 0 & 0 & 0 & 0 & 0 & 0 & 0 & 0 & 3 & 2 & 1 & 5 & 4 & 4 & 3 & 2 & 2 & 0 & 0 & 0 & 26 \\
Gross total count & 12 & 10 & 1 & 0 & 2 & 1 & 1 & 1 & 11 & 2 & 2 & 11 & 17 & 27 & 9 & 14 & 3 & 7 & 4 & 4 & 139 \\
\hline
\end{tabular}


Table 2. Average total counts (ATC, calculated per $\mathrm{g}$ fresh fruit in all samples), percentage counts (\%C, calculated per Aspergillus section Nigri), percentage frequency (\%F, calculated per 20 samples), number of cases of isolation $(\mathrm{NCl}$, out of 20 samples) and occurrence remarks (OR) of various fungal species collected from Pyrus communis fruit samples on MEA medium at $27^{\circ} \mathrm{C}$

\begin{tabular}{|c|c|c|c|c|c|}
\hline Species & ATC & $\mathrm{C} \%$ & $\mathrm{NCl}$ & OR & $\mathrm{F} \%$ \\
\hline A. awamori & 36.7 & 7.9 & 6 & $\mathrm{M}$ & 30 \\
\hline A. niger & 340 & 73.4 & 14 & $\mathrm{H}$ & 70 \\
\hline A. tubingensis & 86.7 & 18.7 & 9 & M & 45 \\
\hline Total count & 463.4 & 100 & & & \\
\hline
\end{tabular}

Table 3. Total Ochratoxin A (PPB) produced by different black aspergilli species isolated from different Pyrus communis samples in CYA medium at $27^{\circ} \mathrm{C}$ for 7 days

\begin{tabular}{llll}
\hline No. & Strain code & Species & OTA level (PPB) \\
\hline 1 & SNM3 & A. awamori & $\mathrm{Nd}$ \\
2 & SNM8 & A. awamori & $\mathrm{Nd}$ \\
3 & SNM10 & A. awamori & $\mathrm{Nd}$ \\
4 & SNM18 & A. awamori & $\mathrm{Nd}$ \\
5 & SNM1 & A. niger & $\mathrm{Nd}$ \\
6 & SNM2 & A. niger & $\mathrm{Nd}$ \\
7 & SNM4 & A. niger & $\mathrm{Nd}$ \\
8 & SNM5 & A. niger & $\mathrm{Nd}$ \\
9 & SNM7 & A. niger & 9.5 \\
10 & SNM9 & A. niger & $\mathrm{Nd}$ \\
11 & SNM11 & A. niger & $\mathrm{Nd}$ \\
12 & SNM12 & A. niger & $\mathrm{Nd}$ \\
13 & SNM14 & A. niger & $\mathrm{Nd}$ \\
14 & SNM15 & A. niger & 2.4 \\
15 & SNM19 & A. niger & 2.5 \\
16 & SNM20 & A. niger & 1.2 \\
17 & SNM21 & A. niger & $\mathrm{Nd}$ \\
18 & SNM22 & A. niger & 0.18 \\
19 & SNM23 & A. niger & $\mathrm{Nd}$ \\
20 & SNM24 & A. niger & $\mathrm{Nd}$ \\
21 & SNM25 & A. niger & 0.95 \\
22 & SNM27 & A. niger & $\mathrm{Nd}$ \\
23 & SNM6 & A. tubingensis & $\mathrm{Nd}$ \\
24 & SNM13 & A. tubingensis & 0.84 \\
25 & SNM16 & A. tubingensis & 1.2 \\
26 & SNM17 & A. tubingensis & 0.3 \\
27 & SNM26 & A. tubingensis & 0.65 \\
\hline
\end{tabular}

$N d$ : not detected with the limit of detection

\section{DISCUSSION}

Three species belonging to black Aspergelli were isolated and identified from Pyrus communis fruit on MEA medium at $27^{\circ} \mathrm{C}$. A. niger was the most common species. A. niger var. niger and Aspergillus niger var. awamori were isolated in highest frequency from black dried vine fruits on DRBC and DG18 media. Where OTA was found in $74 \%$ of the dried vine fruits samples. $A$. carbonarius occupied the first place in the production of OTA, were detected (82.6\%). Followed by Aspergillus section Nigri, so sixty two strains $(28 \%)$ have the ability to produce OTA [34]. The pomegranate trees are not affected by any serious disease however the fruit are often damaged by heart rot caused by different species fungi and bacteria or after invasion of the insect. Twenty-six samples of splitting pomegranate fruits from different garden 
close to Cairo, Egypt were examined, and they showed that they contain a reproductive structure of genus $A$. niger which can reach the guts of the fruits throughout the period of growth until harvest the mature fruits [35].

Among isolates of black Aspergilli, the ranges of OTA in all strains were $0.18-9.5 \mathrm{ppb}$. Fungi producing OTA in Portuguese wine grapes, a survey was conducted in 11 vineyards, from winemaking regions every with different climatic conditions. They isolated 370 strains of Aspergillus and 301 strains of Penicillium from 1650 samples of barriers, the study showed $14 \%$ of the aspergilli were OTA-producing strains. None of the penicillia were OTA-producing strains. The black aspergilli were predominant (90\%). $97 \%$ of black aspergilli were Aspergillus carbonarius and $3 \%$ of the Aspergillus niger collected in this study were OTA producers [36].

Many species of fungi were isolated from five grape varieties grown in Spain. The most fungal genera isolated were Alternaria, Cladosporium, and Aspergillus. The study showed that $82 \%$ Aspergillus sp. section Nigri were OTA-producing strains, was assessed using yeast extractsucrose broth supplemented with $5 \%$ bee pollen. Cultures of 205 isolates from this section appeared that $74.2 \%$ of Aspergillus carbonarius and $14.3 \%$ of Aspergillus tubingensis isolates produced OTA ranging from 1.2 to $3,530 \mathrm{mg} / \mathrm{ml}$ and from 46.4 to $111.5 \mathrm{mg} / \mathrm{ml}$, respectively. No Aspergillus niger isolate had the ability to produce this toxin under the conditions assayed [37].

The total ochratoxin and ochratoxigenic genes (PKS15C-MeT and PKS15KS) detected in 27 strains of ochratoxigenic black aspergilli isolates collected from Pyrus communis samples were showed in Table 4. From those 27 strains, $A$. niger (SNM7, and 19), and $A$. tubingensis (SNM16, and 26) contained the two OTA biosynthesis genes. But, A. niger (SNM20, and 22) contained only PKS15C-MeT gene, while

Table 4. Total ochratoxin A and ochratoxigenic genes (PKS15C-MeT and PKS15KS) detected in 27 strains of black aspergilli isolates collected from pear samples

\begin{tabular}{|c|c|c|c|c|}
\hline No. & Strain code & Total OTA genes & PKS15C-MeT & PKS15KS \\
\hline 1 & SNM1 & - & - & - \\
\hline 2 & SNM2 & - & - & - \\
\hline 3 & SNM3 & - & - & - \\
\hline 4 & SNM4 & - & - & - \\
\hline 5 & SNM5 & - & - & - \\
\hline 6 & SNM6 & - & - & - \\
\hline 7 & SNM7 & + & + & + \\
\hline 8 & SNM8 & - & - & - \\
\hline 9 & SNM9 & - & - & - \\
\hline 10 & SNM10 & - & - & . \\
\hline 11 & SNM11 & - & - & - \\
\hline 12 & SNM12 & - & - & - \\
\hline 13 & SNM13 & + & + & + \\
\hline 14 & SNM14 & - & & $\cdot$ \\
\hline 15 & SNM15 & + & . & + \\
\hline 16 & SNM16 & + & + & + \\
\hline 17 & SNM17 & + & - & + \\
\hline 18 & SNM18 & - & - & - \\
\hline 19 & SNM19 & + & + & + \\
\hline 20 & SNM20 & + & + & . \\
\hline 21 & SNM21 & - & - & . \\
\hline 22 & SNM22 & + & + & - \\
\hline 23 & SNM23 & - & - & . \\
\hline 24 & SNM24 & - & - & . \\
\hline 25 & SNM25 & + & . & + \\
\hline 26 & SNM26 & + & + & + \\
\hline 27 & SNM27 & - & - & - \\
\hline
\end{tabular}




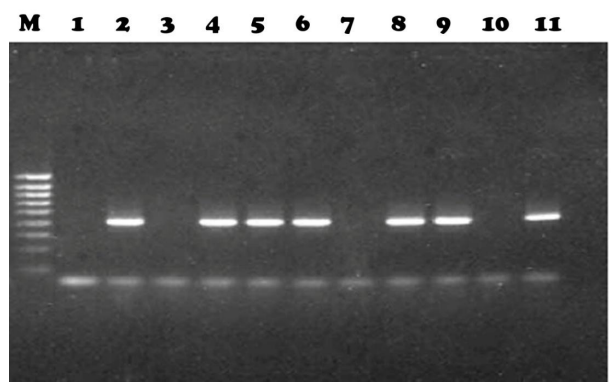

(A)

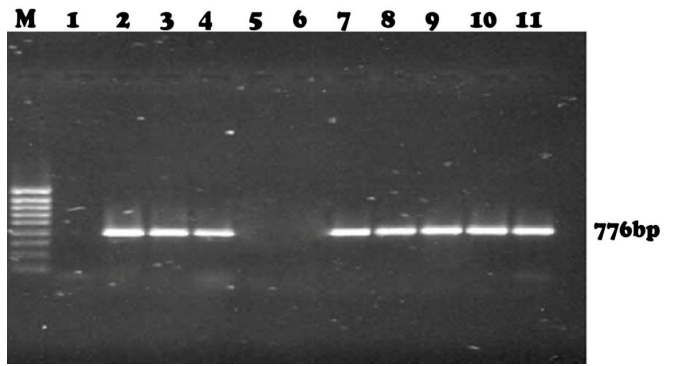

(B)

Fig. 1. Ochratoxin biosynthesis genes amplifications. (A). PKS15C-MeT gene and, (B). PKS15KS gene. M, DNA marker; lane 1, negative control; lanes 2-7, A. niger (SNM 7, 15, 19, 20, 22, and 25); lanes 8-11, A. tubingensis (SNM 13, 16, 17, and 26)

A. niger (SNM15, and 25) and A. tubingensis (SNM17) contained only PKS15KS gene. On the other hand, 17 non ochratoxigenic strains showed no bands, which means that the there is deletion in targeted genes in this isolates. All $A$. awamori strains (SNM3, 8, 10, and 18), A. niger strains (SNM1, 2, 4, 5, 9, 11, 12, 14, 21, 23, 24, and 27), and $A$. tubingensis strain (SNM6) showed no bands. According to the results of [38] study, the aflatoxigenic species of Aspergillus has been shown to vary in their aflatoxin potentials with the substrate and environmental factors. Whereas, the presence of four tested genes is not sufficient marker for differentatin between aflatoxigenic and non aflatoxigenic isolates.

OTA-nonproducing isolates of $A$. niger and $A$. welwitschiae $(A$. awamori) species lacked the OTA biosynthetic gene (OTA) cluster, analysis of genome sequence data revealed a single pattern of OTA gene deletion in the two species. Phylogenetic analysis suggest that the simplest explanation for this is that OTA cluster deletion occurred in a common ancestor of $A$. niger and $A$. welwitschiae, and subsequently both the intact and deleted cluster were retained as alternate alleles during divergence of the ancestor into descendent species. When comparing their results with previous studies indicated that a minority of isolates of both species produce OTA. also, suggested that the relative abundance of each species and frequency of OTA-producing isolates can vary with crop and/or geographic origin [39].

\section{RECOMMENDATIONS}

It is important to reduce the occurrence of black mold in fruits and vegetable at the stages before harvest. Therefore, the control of storage diseases is of great concern with an urgent need to determine the appropriate control measure for each pathogen. improved storage techniques and disease control need to be developed according to climatic regions and storage conditions contaminated fruits and vegetable from the field act as sources of contamination in the storage house; thus, disease control should be considered from the field stage to mitigate the first inoculum of the storage disease.

\section{CONCLUSION}

In this study, black Aspergilli was isolated from 20 samples of Pyrus communis. Most of the samples showed to be contaminated with black Aspergilli. The common black Aspergilli is A. niger. In detection of the ability of these fungi to produce ochratoxin $A$, some of them have the ability to form ochratoxin $A$, the production of these toxins is linked to the presence of one or more genes.

\section{COMPETING INTERESTS}

Authors have declared that no competing interests exist.

\section{REFERENCES}

1. Amusa NA, Kehinde IA, Ashaye OA. Biodeterioration of breadfruit in storage and its effects on the nutrient composition. Afr. J. Biot. 2002;1(2):57-60.

2. Salman MAM. Biological Control of Rhizopus Soft Rot on Apple, Pear and Peach by Trichoderma harzianum. Doctoral Thesis, National University, India; 2005.

3. Parveen S, Wani AH, Bhat MY, Koka JA, Wani FA. Management of postharvest 
fungal rot of peach (Prunus persica) caused by Rhizopus stolonifer in Kashmir Valley, India. Plant Path. Quarantine. 2016;6(1):19-29.

4. Droby S. Improving quality and safety of fresh fruits and vegetables after harvest by the use of biocontrol agents and natural materials. Acta Horticul. 2006;709:45-51.

5. Zhu SJ. Non-chemical approaches to decay control in postharvest fruit. In: Noureddine, B., Norio, S. (Eds.), Advances in Postharvest Technologies for Horticultural Crops. Research Signpost, Trivandrum, India. 2006;297-313.

6. Valiuskaite $A$, Kvikliene $\mathrm{N}$, Kviklys D, Lanauskas J. Post-harvest fruit rot incidence depending on apple maturity. Agronomy Research 4 (Special Issue). 2006;427-431.

7. Ewekeye TS, Oke OA, Esan O. Studies on post harvest rot of apple (Malus domestica Borkh). Ind. J. Plant Sci. 2016;5(1):36-41.

8. Sommer NF. Strategies for control of postharvest disease of selected commodities. In: Post-harvest Technology of Horticultural Crops. University of California Press. 1985;83-98.

9. Magan N, Aldred D. Post-harvest control strategies: Minimizing mycotoxins in the food chain. Inter. J. Food Micro. 2007; 119(1-2):131-139.

10. Šegvić Klarić $M$. Adverse effects of combined mycotoxins. Arh. Hig. Rada. Toksikol. 2012;63:519-30.

11. Chiotta ML, Ponsone ML, Sosa DM, Combina M, Chulze SN. Biodiversity of Aspergillus section Nigri populations in Argentinian vineyards and ochratoxin A contamination. Food Microb. J. 2013; 36(2):182-90.

12. Månsson $\mathrm{M}$, Klejnstrup $\mathrm{ML}$, Phipps RK, Nielsen KF, Frisvad JC, Gotfredsen $\mathrm{CH}$. Isolation and NMR characterization of fumonisin B2 and a new fumonisin B6 from Aspergillus niger. J. Agri. Food Chem. 2010;58(2):949-53.

13. Frisvad JC, Larsen TO, Thrane U, Meijer M, Varga J, Samson RA, Nielssen KF. Fumonisin and ochratoxin production in industrial Aspergillus niger strains. PLoS ONE. 2011;6,e23496.

14. Piecková E. Adverse health effects of indoor moulds. Arh. Hig. Rada. Toksikol. 2012;63:545-9.

15. Blumenthal CZ. Production of toxic metabolites in Aspergillus niger, Aspergillus oryzae, and Trichoderma reesei: justification of mycotoxin testing in food grade enzyme preparations derived from the three fungi. Reg. Toxi. Pharm. 2004;39(2):214-28.

16. Nielsen KF, Mogensen JM, Johansen M, Larsen TO, Frisvad JC. Review of secondary metabolites and mycotoxins from the Aspergillus niger group. Anal. Bioanal. Chem. 2009;395:1225-46.

17. Sharma R. Pathogenicity of Aspergillus niger in plants. Cibtech. J. Microb. 2012;1(1):47-51.

18. Schwab CJ, Straus DC. The roles of Penicillium and Aspergillus in sick building syndrome. Adv. Appl. Microbiol. 2004;55: 215-38.

19. Samson RA, Houbraken J, Thrane U, Frisvad JC, Andersen B. Food and indoor fungi., Utrecht: CBS-KNAW Fungal Biodiversity Centre; 2010.

20. Samson RA, Noonim $P$, Meijer $M$, Houbraken J, Frisvad JC, Varga J. Diagnostic tools to identify black Aspergilli. Stud Mycol. 2007;59:129-45.

21. Abarca ML, Bragulat MR, Castellà G, Cabańes FJ. Ochratoxin A production by strains of Aspergillus niger var. niger. Appl. Environ. Microb. 1994;60:2650-2.

22. Joosten HMLJ, Goetz J, Pittet $A$, Schellenberg M, Bucheli P. Production of ochratoxin A by Aspergillus carbonarius on coffee cherries. Int. J. Food Microbiol. 2001;65:39-44.

23. Lucchetta G, Bazzo I, Dal Cortivo G, Stringher L, Bellotto D, Borgo M. Occurrence of black Aspergilli and ochratoxin A on grapes in Italy. Toxins. 2010;2:840-55.

24. Gautam AK, Sharma S, Avasthi S, Bhadauria R. Diversity, pathogenicity and toxicology of $A$. niger: an important spoilage fungi. Res. J. Microbiol. 2011;6: 270-80.

25. International Agency for Research on Cancer. Some naturally occurring substances; food items and constituents, heterocyclic aromatic amines and mycotoxins. IARC monographs on the evaluation of carcinogenic risks to humans. 1993;56:1-489.

26. Magnoli CE, Astoreca AL, Chiacchiera SM, Dalcero AM. Occurrence of ochratoxin A and ochratoxigenic mycoflora in corn and corn based foods and feeds in some South American countries. Mycopathologia. 2007;163:249-60. 
27. Logrieco A, Ferracane R, Haidukowsky $M$, Cozzi G, Visconti A, Ritieni A. Fumonisin B2 production by Aspergillus niger from grapes and natural occurrence in must. Food Addit. Contam. 2009;26:1495-1500.

28. Mogensen JM, Frisvad JC, Thrane U, Nielsen KF. Production of fumonisin B2 and B4 by Aspergillus niger on grapes and raisins. J. Agric. Food Chem. 2010;58: 954-8.

29. Wilson DM. In: Mycotoxins. DeVries JW, Trucksess MW, Jackson LS, editors. Kluwer Academic/ Plenum Publishers; New York. Food Saf. 2002;5-17.

30. Gherbawy $Y$, Elhariry $H$, Kocsubé $S$, Bahobial A, El-Deeb B, Altalhi A, Varga J, Vágvölgyi C. Molecular characterization of black Aspergillus species from onion and their potential for ochratoxin $A$ and fumonisin B2 production. Foodborne Path. Dis. 2015;1:1-9.

31. Ben Fredj SM, Chebil S, Mliki A. Isolation and characterization of ochratoxin $A$ and aflatoxin B1 producing fungi infecting grapevines cultivated in Tunisia. Afr. J. Microb. Res. 2009;3(9):523-527.

32. Jin L, Szeto KY, Zhang L, Du W, Sun $H$. Inhibition of alcohol dehydrogenase by bismuth. J. Inorg. Biochem. 2004;98(8): 1331-7.

33. White PA, Stokes HW, Bunny KL, Hall RM. Characterisation of a chloramphenicol acetyltransferase determinant found in the chromosome of Pseudomonas aeruginosa. FEMS Microbiology Letters. 1999;175: 227-235.
34. Magnoli C, Astoreca A, Ponsone L, Combina M, Palacio G, Rosa CAR, Dalcero AM. Survey of mycoflora and ochratoxin $A$ in dried vine fruits from Argentina markets. Let. Appl. Microbiol. 2004;39:326-331.

35. Yehia HM. Heart rot caused by Aspergillus niger through splitting in leathery skin of pomegranate fruit. Afr. J. Microb. Res. 2013;7(9):834-837.

36. Serra R, Abrunhosa L, Kozakiewicz Z, Venancio A. Black Aspergillus species as ochratoxin A producers in Portuguese wine grapes. Inter. J. Food Microb. 2003;88: 63-68.

37. Medina A, Mateo R, Lopez-Ocana L, ValleAlgarra FM, Jimenez M. Study of Spanish grape mycobiota and ochratoxin A production by isolates of Aspergillus tubingensis and other members of Aspergillus Section Nigri. App. Envir. Microb. 2005;71(8):4696-4702.

38. Gherbawy YA, Shebany YM, Alharthy HF. Molecular characterization of aflatoxigenic aspergilli-contaminated poultry and animal feedstuff samples from the western region of Saudi Arabia. Italian J. Food Sci. 2016;28:32-42.

39. Susca A, Proctor RH, Morelli $M$, Haidukowski M, Gallo A, Logrieco AF, Moretti A. Variation in fumonisin and ochratoxin production associated with differences in biosynthetic gene content in Aspergillus niger and $A$. welwitschiae isolates from multiple crop and geographic origins. Frontiers Microb. 2016;7:1412.

(C) 2018 Shebany et al.; This is an Open Access article distributed under the terms of the Creative Commons Attribution License (http://creativecommons.org/licenses/by/4.0), which permits unrestricted use, distribution, and reproduction in any medium, provided the original work is properly cited. http://www.sdiarticle3.com/review-history/47496 